\title{
Solusi Numerik Persamaan Logistik dengan Menggunakan Metode Dekomposisi Adomian Dan Metode Milne
}

\author{
Elis Ratna Wulan, Fahmi Hasanudin \\ Jurusan Matematika, Fakultas Sains dan Teknologi, \\ UIN Sunan Gunung Djati Bandung \\ JL. A. H. Nasution No 105 Bandung 40614 \\ elisrwulan@yahoo.com, lazuardi8@gmail.com
}

\begin{abstract}
ABSTRAK
Persamaan logistik merupakan persamaan diferensial yang autonomous sehingga memiliki nilai kesetimbangan. Paper ini membahas solusi persamaan logistik menggunakan pendekatan numerik Metode Dekomposisi Adomian dan Metode Milne. Dilihat dari kesalahan per langkah pada penyelesaian numerik persamaan logistik, Metode Dekomposisi Adomian menghasilkan tingkat akurasi yang lebih baik untuk orde yang makin tinggi daripada Metode Milne. Sehingga Metode Dekomposisi Adomian untuk orde yang lebih besar lebih stabil dari Metode Milne.

Kata kunci: Persamaan diferensial biasa taklinear, Persamaan logistik, Metode Dekomposisi Adomian, Metode Milne

\section{ABSTRACT}

Logistic equation is autonomous differential equations that has equilibrium value. This paper discusses the logistic solution using Adomian Decomposition Method and Milne Method numerical approximation. Jugding from the error in the logistic equations numerical solution per step, Adomian Decomposition Method produces a better accuracy rate for higher order than the Milne Method. So Adomian Decomposition Method to order the larger more stable than Milne Method.

Keywords: Nonlinear ordinary differential equation, Equation logistics, Adomian Decomposition Method, Milne Method.
\end{abstract}

\section{Pendahuluan}

Persamaan logistik atau persamaan Verhulst merupakan salah satu persamaan model pertumbuhan populasi, yang secara matematis:

dengan kondisi batas

$$
\frac{d N}{d t}=r N\left(1-\frac{N}{K}\right)
$$

$$
N(0)=N_{0}
$$

di mana $N$ didefinisikan jumlah populasi pada waktu $(t), r$ didefinisikan laju pertumbuhan hakiki (intrinsik), dan $K$ didefinisikan kapasitas pembawaan (carrying capacity). 
Persamaan logistik merupakan persamaan diferensial biasa taklinear yang autonomous. Artinya persamaan logistik tidak mengandung variabel bebas secara eksplisit atau variabel bebasnya hanya muncul pada derivatif. Nilai kesetimbangan pada persamaan logistik diperoleh ketika $\frac{d N}{d t}=0$, sehingga nilai kesetimbangannya berada pada $N=0$ dan $N=K$. Persamaan logistik menggambarkan proses pertumbuhan populasi yang dibatasi, sehingga jumlah populasinya tidak bertambah tak terhingga dan akan selalu terbatas pada suatu nilai tertentu. Nilai kesetimbangan $K$ merupakan batas pertumbuhan dari jumlah populasi. Oleh karena itu, pada waktu tertentu jumlah populasi akan bergerak menuju nilai kesetimbangan dan tidak melewati tetapi hanya mendekati.

Persamaan logistik dapat diselesaikan secara analitik maupun secara numerik. Pada paper ini penyelesaian persamaan logistik menggunakan Metode Dekomposisi Adomian dan Metode Milne, karena Metode Dekomposisi Adomian terbukti dapat menyelesaikan persamaan diferensial baik yang linear ataupun yang taklinear. Persamaan diferensial yang diselesaikan menggunakan Metode Dekomposisi Adomian memberikan solusi yang mendekati solusi eksak (Nouvri et al [4]). Metode Dekomposisi Adomian merupakan solusi persamaan diferensial dengan memisalkannya ke dalam bentuk deret (Dukkipati,[2]). Keunggulan Metode Dekomposisi Adomian adalah kekonvergenan yang dapat mencapai untuk orde yang makin tinggi yang dinyatakan dalam solusi deret (Cano [1]).

Metode lain yang dapat digunakan untuk menyelesaikan persamaan logistik adalah Metode Milne. Metode Milne merupakan salah satu penyelesaian numerik persamaan diferensial biasa. Metode Milne adalah metode multi-step yang pendekatannya menggunakan prediktor dan korektor. Metode Milne didasarkan pada rumus terbuka Newton Cotes dan rumus tertutup Newton Cotes untuk menyelesaikan sebuah persamaan matematika. Keunggulan Metode Milne adalah memiliki tingkat akurasi yang tinggi (Gavrilyuk et. al.,[3]), akan tetapi kekonsistenan Metode Milne dalam beberapa hal masih diragukan, namun dari itu penulis ingin menggunakan Metode Milne dalam menyelesaikan persamaan logistik ini.

Bentuk umum persamaan pertumbuhan logistik didefinisikan (lihat Tsoularis [5])

$$
\frac{d N}{d t}=r N^{\alpha}\left[1-\left(\frac{N}{K}\right)^{\beta}\right]^{\gamma}
$$

di mana $\alpha, \beta$, dan $\gamma$ adalah nilai real positif.. Bentuk umum persamaan pertumbuhan logistik [1] merupakan gabungan dari beberapa model kasus khusus diantaranya model persamaan eksponensial, model pertumbuhan logistik, model pertumbuhan generik, dan model von Bertalanffy, persamaan pertumbuhan Ricard's, seperti pada Gambar 1. 


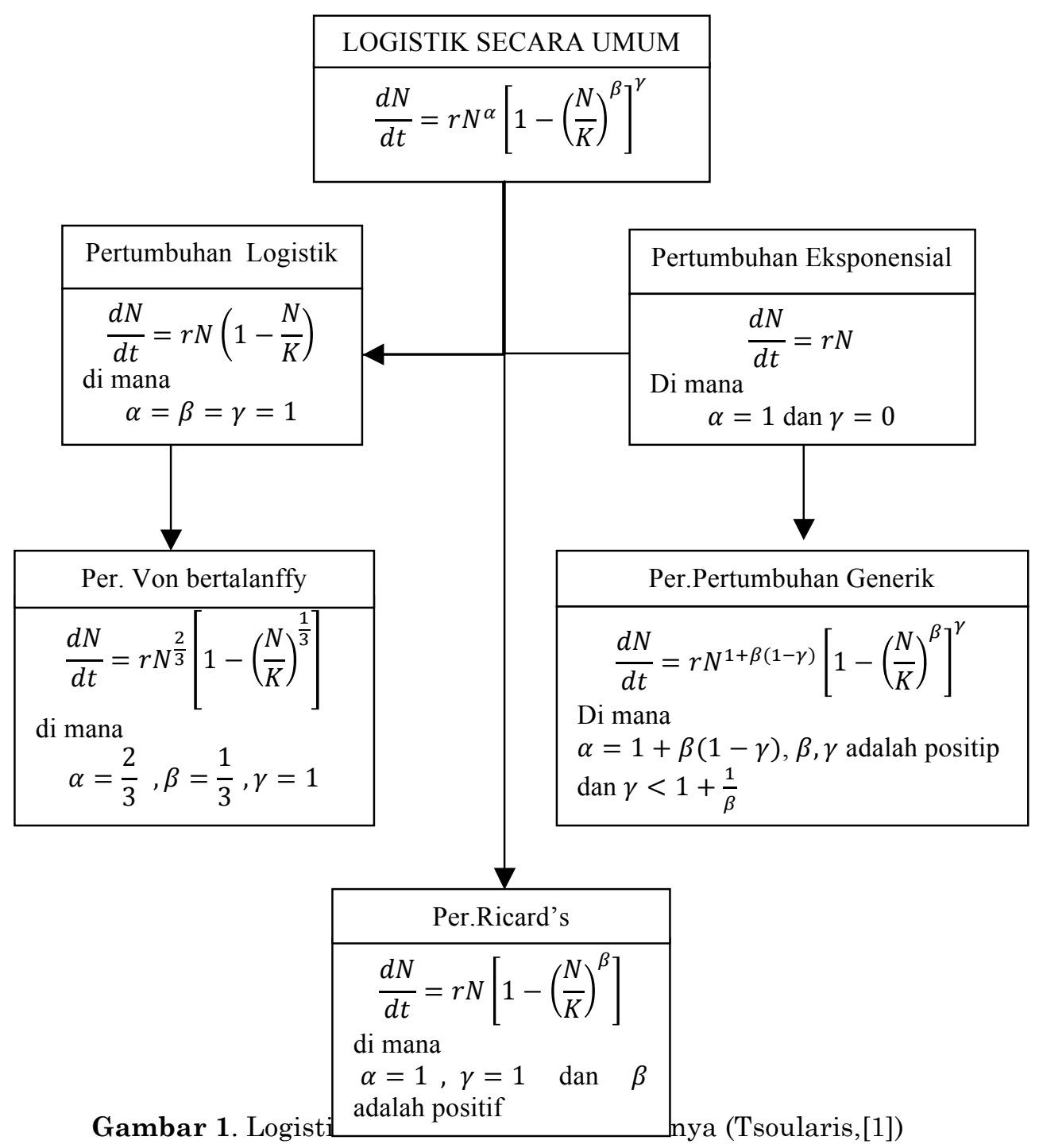

Gambar 1 menjelaskan persamaan logistik secara umum. Untuk $\alpha, \beta$, dan $\gamma$ yang berbeda akan diperoleh persamaan logistik khusus.

\section{Kajian Pustaka}

\subsection{Metode Dekomposisi Adomian}

Salah satu metode untuk menyelesaikan persamaan logistik adalah Metode Dekomposisi Adomian yang diperkenalkan oleh George Adomian pada 
tahun 1980. Metode Dekomposisi Adomian merupakan solusi persamaan diferensial dengan memisalkannya ke dalam bentuk deret (Dukkipati,[2]).

Langkah penyelesaian menggunakan Metode Dekomposisi Adomian:

1. Misalkan persamaan diferensial biasa ke dalam bentuk persamaan

$$
(L+R+N) y=G \text { ata } L y=G+R y+N y
$$

di mana $()=.\left(\frac{d}{d x}\right)(),$.$R operator linier dan N$ menggambarkan bentuk taklinear dari persamaan diferensial.

2. Kalikan $L^{-1}$ sehingga memperoleh solusi persamaan

$$
y=L^{-1} G+L^{-1} R y+L^{-1}
$$

di mana $L^{-1}=\int_{x_{0}}^{x}() d$.$s merupakan invers dari L$.

3. Misalkan solusi pada persamaan ke dalam deret

$$
y=\sum_{n=0}^{\infty} y_{n} \text { dan } N y=\sum_{n=0}^{\infty} A_{n}
$$

di mana setiap $A_{n}$ merupakan adomian polinomial yang tergantung pada $y_{0}, y_{1}, y_{2}, y_{3}, \ldots, y_{n}$ yang diberikan oleh

$$
A_{n}\left(y_{0}, y_{1}, y_{2}, y_{3}, \ldots, y_{n}\right)=\frac{1}{n !}\left[\frac{d^{n}}{d \lambda^{n}} N\left(\sum_{i=0}^{n} y_{t} \lambda^{t}\right)\right]_{\lambda=0}
$$

4. Menentukan

$$
\begin{aligned}
& y_{0}=L^{-1} G \\
& y_{k+1}=-L^{-1}\left(R y_{n}\right)-L^{-1}\left(A_{n}\right)
\end{aligned}
$$

\subsection{Metode Milne}

Metode berikutnya yang dapat digunakan untuk menyelesaikan persamaan logistik adalah Metode Milne. Metode Milne dirumuskan sebagai berikut [5]:

$$
\begin{aligned}
& \text { Prediktor: } y_{n+1}=y_{n-3}+\frac{4 h}{3}\left(2 f_{n}-f_{n-1}+2 f_{n-2}\right) \\
& \text { Korektor : } y_{n+1}=y_{n-1}+\frac{h}{3}\left(f_{n-1}+4 f_{n}+f_{n+1}\right)
\end{aligned}
$$

\section{Pembahasan}

Dalam penelitian Tsaoularis terdapat suatu model pertumbuhan populasi dengan kapasitas pembawaan 100 dan laju pertumbuhan 0,9 [1], secara matematis maka persamaan logistik tersebut dapat ditulis

dengan kondisi awal

$$
\frac{d y}{d t}=0,9 y\left(1-\frac{y}{100}\right)
$$

$$
y(0)=10
$$

di mana pada saat $x=0$, populasinya adalah 10 . Persamaan (7) mempunyai solusi analitik

$$
y(t)=\frac{(10)(100)}{(10)+(100-10) e^{-(0,9) x}}
$$

Sehingga solusi analitik persamaan (11) mempunyai grafik yang dapat dilihat dalam Gambar 2. 


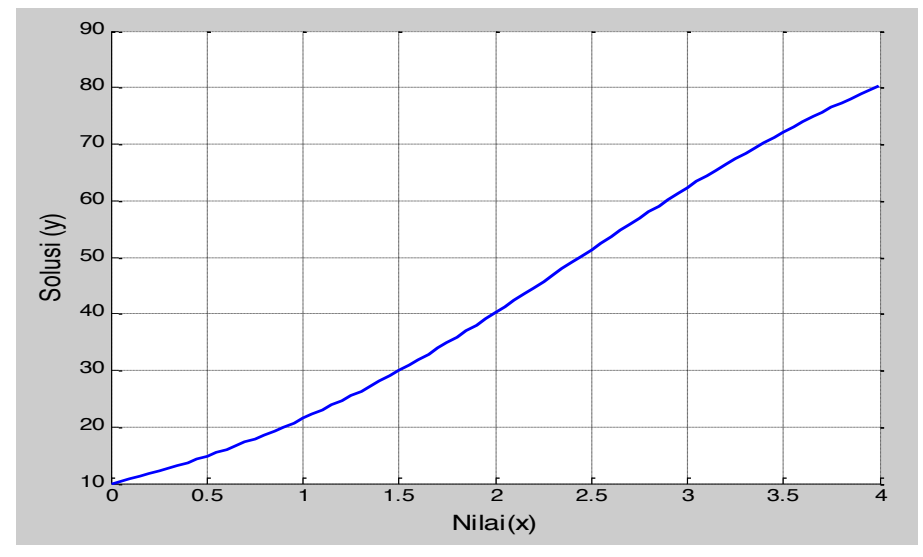

Gambar 2. Grafik solusi analitik persamaan logistik (11)

Untuk melihat grafik solusi persamaan logistik (11) dengan menggunakan Metode Dekomposisi Adomian untuk $\mathrm{n}=2, \mathrm{n}=5, \mathrm{n}=10, \mathrm{n}=15$, $\mathrm{n}=20$, dan $\mathrm{n}=202$ dapat dilihat pada Gambar 3 berikut. Nilai $\mathrm{n}$ diambil secara acak untuk menunjukkan simulasi persamaan logistik.

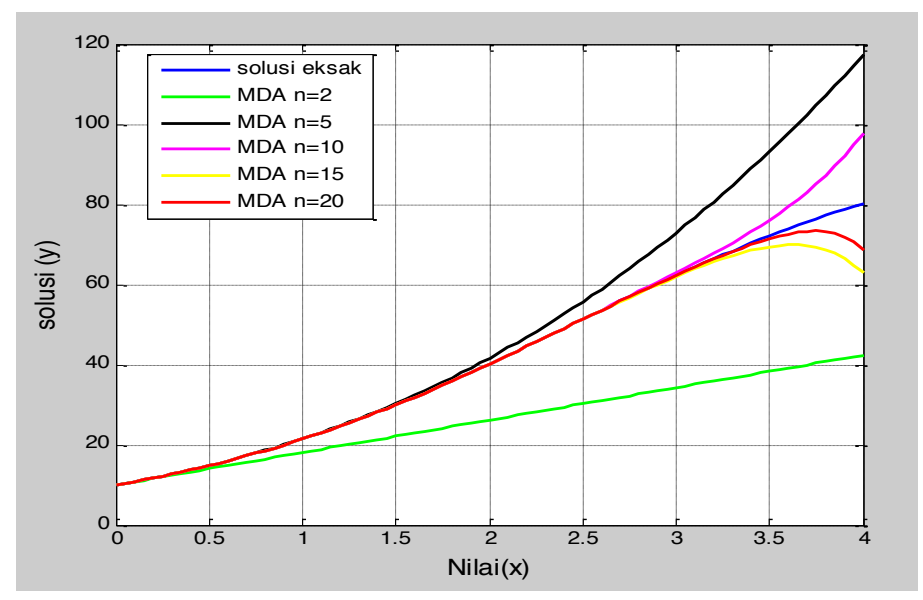

Gambar 3.a. Solusi persamaan logistik (11) dengan menggunakan Metode Dekomposisi Adomian untuk $\mathrm{n}=2, \mathrm{n}=5, \mathrm{n}=10, \mathrm{n}=15$ 


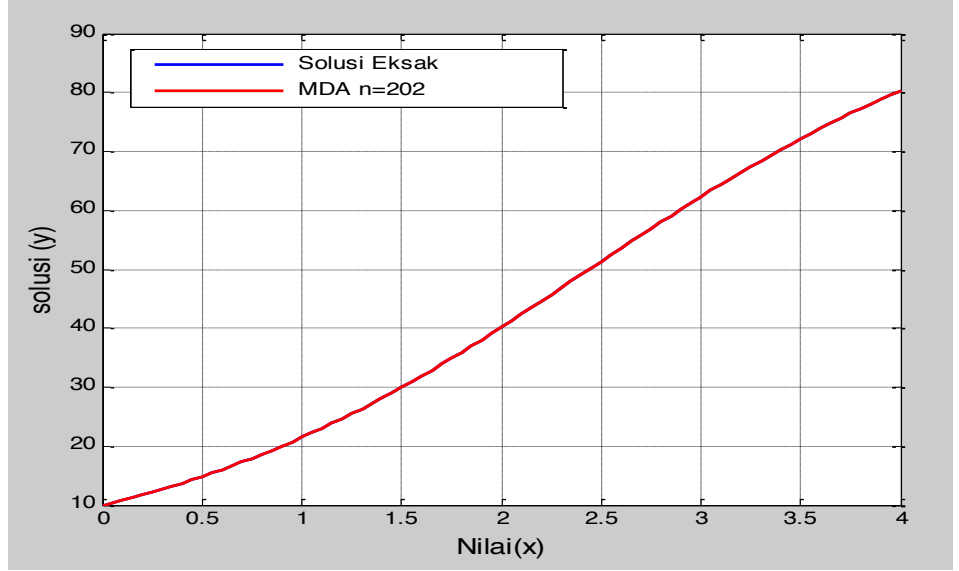

Gambar 3.b. Solusi persamaan logistik (11) dengan menggunakan Metode Dekomposisi Adomian untuk n= 202

Untuk grafik solusi persamaan logistic (11) menggunakan Metode Milne dapat dilihat pada gambar 4 .

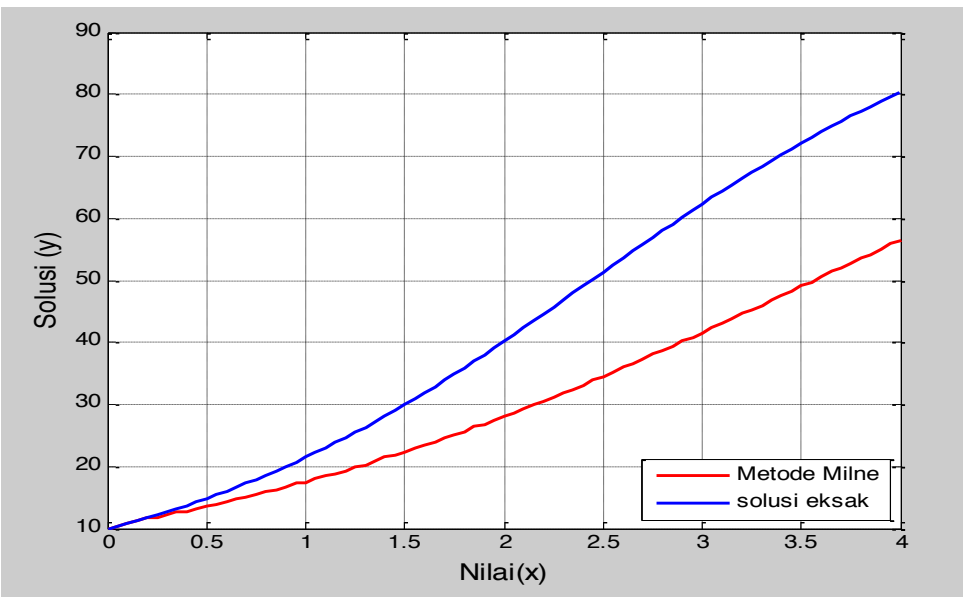

Gambar 4. Grafik solusi persamaan logistik menggunakan Metode Milne

Akurasi dan kestabilan Metode Dekomposisi Adomian dan Metode Milne pada persamaan logistik (7) terlihat pada kesalahan per langkah solusi aproksimasi terhadap solusi analitik. Untuk lebih jelasnya disajikan pada Tabel 1. 
Tabel 1. Kesalahan solusi aproksimasi persamaan logistik dengan menggunakan Metode Dekomposisi Adomian dan Metode Milne

\begin{tabular}{|c|c|c|c|c|c|c|}
\hline \multirow{3}{*}{$\mathrm{X}$} & \multicolumn{6}{|c|}{$\begin{array}{c}\text { Kesalahan per langkah solusi aproksimasi terhadap solusi analitik studi kasus persamaan } \\
\text { logistic }\end{array}$} \\
\hline & \multicolumn{5}{|c|}{ Metode Dekomposisi Adomian } & \multirow[t]{2}{*}{ Metode Milne } \\
\hline & $\mathrm{n}=2$ & $\mathrm{n}=3$ & $\mathrm{n}=4$ & $\mathrm{n}=5$ & $\mathrm{n}=6$ & \\
\hline 0 & 0 & 0 & 0 & 0 & 0 & 0 \\
\hline 0,2 & 0,010274 & 0.00033968 & $3.0679 \mathrm{e}-006$ & $9,2204 \mathrm{e}-007$ & $4.329 \mathrm{e}-008$ & $2,9694 \mathrm{e}-009$ \\
\hline 0,4 & 0,036249 & 0.0022876 & $5.5748 \mathrm{e}-005$ & $2,6406 \mathrm{e}-005$ & $2.3743 \mathrm{e}-006$ & 0,071502 \\
\hline 0,6 & 0,072032 & 0.0064778 & 0.00030715 & 0,00017971 & $2.3153 \mathrm{e}-005$ & 0,10717 \\
\hline 0,8 & 0,11325 & 0.012831 & 0.0010267 & 0,00067968 & 0.00011123 & 0,13814 \\
\hline 1 & 0,1567 & 0.020838 & 0.002598 & 0,0018643 & 0.00036221 & 0,18754 \\
\hline 1,2 & 0,20009 & 0.029758 & 0.0055002 & 0,0041758 & 0.00092154 & 0,2154 \\
\hline 1,4 & 0,24181 & 0.038754 & 0.010285 & 0,008136 & 0.0019754 & 0,23675 \\
\hline 1,6 & 0,28081 & 0.046984 & 0.017553 & 0,01432 & 0.0037309 & 0,26896 \\
\hline 1,8 & 0,31641 & 0.053656 & 0.027929 & 0,023332 & 0.0063892 & 0,28713 \\
\hline 2 & 0,34823 & 0.058061 & 0.042046 & 0,035778 & 0.010112 & 0,29871 \\
\hline 2,2 & 0,3761 & 0.059591 & 0.060525 & 0,052253 & 0.01499 & 0,31687 \\
\hline 2,4 & 0,40003 & 0.057741 & 0.083968 & 0,073322 & 0.021004 & 0,32513 \\
\hline 2,6 & 0,42013 & 0.05211 & 0.11295 & 0,099511 & 0.027995 & 0,32736 \\
\hline 2,8 & 0,43655 & 0.04239 & 0.14799 & 0,1313 & 0.035635 & 0,33403 \\
\hline 3 & 0,44954 & 0.02836 & 0.1896 & 0,16913 & 0.043398 & 0,33332 \\
\hline 3,2 & 0,45933 & 0.0098734 & 0.23823 & 0,21337 & 0.050535 & 0,32747 \\
\hline 3,4 & 0,46619 & 0.013153 & 0.29428 & 0,26436 & 0.056059 & 0,32527 \\
\hline 3,6 & 0,47037 & 0.040748 & 0.35815 & 0,32238 & 0.058721 & 0,31742 \\
\hline 3,8 & 0,47214 & 0.0729 & 0.43017 & 0,38767 & 0.057002 & 0,3055 \\
\hline 4 & 0,47173 & 0.10956 & 0.51065 & 0,46043 & 0.049097 & 0,29727 \\
\hline
\end{tabular}

\section{Simpulan}

Metode Dekomposisi Adomian memiliki tingkat akurasi dan kestabilan yang lebih baik daripada Metode Milne untuk orde $\mathrm{n}>3$. Hal ini dilihat dari kesalahan per langkah pada masing-masing metode. Kesalahan Metode Dekomposisi Adomian pada orde $\mathrm{n}>3$ sebesar 0.00030715 dan kesalahan Metode Milne pada orde $\mathrm{n}>3$ sebesar 0,10717. Sehingga dapat disimpulkan, solusi dengan menggunakan Metode Dekomposisi Adomian lebih mendekati solusi eksak dibandingkan dengan Metode Milne pada persamaan logistik.

\section{Daftar Pustaka}

1. Cano, J.A.S., 2011., Adomain Decomposition Method for A Class of Nonlinear Problems. International Scholarly Research Network, volume 2011, article ID 709753. 
2. Dukkipati, R. V., 2010., Numerical Methods. New Age International (P) Limited, Publishers. USA.

3. Gavrilyuk, I.P., Lazurchak, I.I., Makarov, V.L., dan Sytnyk, D., 2009., A Method with A Controllable Exponential Convergence Rate For Nonlinear Differensial Operator Equations. Computation Method in Applied Mathematichs. 9(1); 63-78.

4. Nouvri K, Garshasbi, M., Damirchi, J., 2008., Application of Adomian Decomposition Method to Solve a Class of Diffusion Problem Arises During MRI. Mathematical Sciences. (2); 207-218.

5. Tsoularis, A., 2001., Analysis of Logistic Growth Model. Res. Lett. Inf. Math. Sci. (2); 23-24. 